\title{
NORMAN—network of reference laboratories, research centres and related organisations for monitoring of emerging substances
}

\author{
Valeria Dulio • Jaroslav Slobodnik
}

Received: 3 December 2008 /Accepted: 14 December 2008/Published online: 5 May 2009

(C) Springer-Verlag 2009

\section{Introduction}

The current priority targets for monitoring activity in aquatic media are still largely focused on conventional pollutants. But is it possible to continue to ignore all the other substances (potential pollutants) currently in use? The answer is clearly no. There are great numbers of emerging substances (among them, pharmaceuticals, phytosanitary products, surfactants, personal care products, etc.) that are potentially responsible for adverse environmental effects. The need to look beyond the traditional/conventional target pollutants when assessing the hazards of chemicals to human health and to ecosystems is now generally recognised as a priority issue in all policy areas at both the European level and the national level in the various European countries. However, it is not possible for individual countries alone to develop the knowledge and methodologies needed for measuring and evaluating the effects and associated risks of a vast number of emerging pollutants.

ESPR Special Issue - ESTROM

Responsible editor: Walter Giger.

V. Dulio $(\bowtie)$

INERIS, Direction Scientifique, Meteorology of the Environment,

Parc Technologique, Alata B.P. 2,

60550 Verneuil-en-Halatte, France

e-mail: valeria.dulio@ineris.fr

J. Slobodnik

Environmental Institute,

Okruzna 784/42,

97241 Kos, Slovak Republic

e-mail: slobodnik@ei.sk
Further to these priority needs, the European Commission launched a call under the 6th Framework Programme in 2004 for the creation of a European network of reference laboratories and research institutes which would help to foster long-term collaboration among European countries for the exchange of information on emerging environmental pollutants for which EU-wide data are lacking, as well as the validation and harmonisation of measurement methods and monitoring tools, which is an essential condition for data comparability and a solid scientific basis for decisionmaking.

\section{The scope of activities NORMAN network}

The NORMAN network (http://www.norman-network. net) started its activities in September 2005 with 17 partners and operated with the financial support of the Commission for 3 years (NORMAN Contract No 018486), with the aim of preparing the ground for the continuation of the work as an extended, self-sustaining network.

The scope of the work of the network is not limited to emerging substances in the water compartment. NORMAN looks at the whole life-cycle of an emerging substance in all environmental media, but we will focus here on the aspects relating to the implementation of the Water Framework Directive (WFD) and the current debate on emerging substances in the water compartment.

The Water Framework Directive plays a key role in the inclusion of emerging pollutants as future priority substances. The work on the revision of the first list of priority substances, which started in 2006 (and is still under way at the time of writing), and the negotiation 
around the EQS Directive ${ }^{1}$ (2006/0129 (COD)), with the proposal from the European Parliament for the inclusion of 30 new substances (including various emerging pollutants), as priority substances, show, on the one hand, the constant pressure from the public for the inclusion of emerging substances as candidate priority substances. On the other hand, they show the importance of an efficient exchange of information about these substances (level of occurrence in the environment, fate and transport, effects, reliability and comparability of the data, etc.) in order to facilitate the risk assessment and prioritisation process by the European Commission.

Member States are currently in the process of identifying the substances that are relevant at a river basin level (i.e. pollutants which are likely to cause a large number of water bodies within the river basin district to fail the objective of 'good ecological status'). The identification of these substances in the various countries is a hot topic at the moment (with many implications, including economic ones).

\section{Concrete achievements}

During the NORMAN project, concrete contributions were provided to help the scientific and technical debate about emerging pollutants under the WFD, with an overview of the latest topics of concern, research needs and priorities for the identification of emerging substances as future priority substances under the WFD.

NORMAN has developed three web-based databases: EMPOMAP, a database of leading experts, organisations and projects dealing with emerging substances; EMPODAT, a database of geo-referenced monitoring data accompanied by ecotoxicological information from bio-assays and biomarkers; and EMPOMASS, a database of mass spectrometric information on provisionally identified and unknown substances. All these databases are publicly available and should contribute to the reduction of current gaps in accessibility and exploitation of the information on emerging substances, thereby providing the ground for the revision of the list of priority substances of the WFD.

A validation protocol for chemical and biological monitoring methods has been developed by the NORMAN experts to provide a common European approach to methods validation. This validation protocol is a piece of concrete support for chemical experts and biologists concerned with the monitoring of these substances in the environment and the identification of their effects. It also

\footnotetext{
${ }^{1}$ DIRECTIVE OF THE EUROPEAN PARLIAMENT AND OF THE COUNCIL on environmental quality standards in the field of water policy, amending and subsequently repealing Directives 82/176/EEC, 83/513/EEC, 84/156/EEC, 84/491/EEC and 86/280/EEC, and amending Directive 2000/60/EC.
}

helps to meet the need to ensure good comparability and reliability of the data for a sound risk assessment.

Four workshops were organised by NORMAN during the course of the project and various other activities were started, such as the establishment of a network of National Contact Points and the publication of a newsletter with critical reviews of recent scientific papers, etc. in order to improve the exchange and accessibility of information and encourage debate among the stakeholders. A research agenda with a list of priority research topics for the future work programme under the 7th Framework Programme of the DG RTD was prepared as a result of the conclusions of the NORMAN work from 2005 to 2008.

The efforts of the NORMAN network during the 3 years of the EU contract earned its recognition as the reference panel of experts at the European level on all issues connected with emerging substances and the associated risks to the environment and health. It is therefore a natural progression to take forward the work of the NORMAN network by creating a non-profit association which is funded by its members and which bases its activities on a strong synergy with the various activities funded at the national level in the field of emerging substances.

NORMAN will organise a number of activities, including expert group meetings, workshops, databases and methods validation exercises. NORMAN will ensure the maintenance of the databases developed during the EUfunded project and will regularly add to them with new data provided by members and Contact Points.

\section{The NORMAN programme of activities for 2009-2011}

The programme of activities of the network for 2009-2011 was presented at the NORMAN Launch Meeting that was held in Paris on 20-21 October.

The goal of the network for 2009-2011 is to stimulate discussion and build a more structured, common approach for the identification of 'emerging' compounds and risk assessment of emerging substances, including all aspects related to the use of chemical and biologically integrated approaches for the identification of 'relevant pollutants'. Today, we still lack the capacity to capture those substances which are really emerging in a European context, and to distinguish them from those 'believed' to be emerging.

Among NORMAN's main activities in 2009 will be:

- A working group on "Prioritisation of emerging substances" aimed at providing a system for prioritisation to identify which substances deserve higher priority for further investigations based on agreed criteria, such as their (eco)toxicity, persistence, bioaccumulation, spatial and temporal distribution, occurrence levels, use, etc. 
- A workshop on 'Emerging pollutants in the WFD: Support for identification of river basin-specific pollutants through NORMAN-MS strategies and needs' which will be organised by the European Commission Joint Research Centre-JRC-IES in Ispra, addressing the MSs' needs in their strategies for the identification of the relevant pollutants of concern.

- A wide-scope workshop organised by RIVM in the Netherlands on all aspects related to the formation of metabolites and degradation products of the target substances, which is a hot topic when discussing emerging contaminants and their associated risks.

- An Expert Group meeting which will lead to a position paper of the NORMAN network on the state of the art and the performance achieved in the use of passive samplers for emerging chemicals, in particular for polar compounds.

- An Expert Group meeting and a working group on the use of biological tools: in vitro, in vivo assays and omics in combination with chemical analysis to assess the risks of environmental pollution in different matrices, and provide information on the modes of action of substances in samples.

\section{Conclusions}

A priority research need highlighted by various research projects and outcomes of recent monitoring programmes in European river basins is a better understanding of the adverse effects of emerging substances on the ecosystems. NORMAN, as a network of reference laboratories, research centres and related organisations in the field of emerging substances, plays a crucial role in the development of knowledge about pollutants, which are of emerging concern in the European context today and the transfer of this knowledge to the decision-makers.

\section{Appendix}

Reference and additional relevant information about the NORMAN network

NORMAN website: http://norman-network.net

NORMAN list of emerging substances: http:/www. norman-network.net/index_php.php?module=public/about us/emerging\&menu2=public/about_us/about_us

\section{Links to NORMAN databases:}

EMPOMAP: http://www.ei.sk/norman/empomap/

EMPODAT : http://www.ei.sk/norman/empodat/

EMPOMASS : http://www.ei.sk/norman/empomass/

\section{NORMAN common protocol for validation} of measurement methods

http://www.norman-network.net/public_docs/norman v1_v2_v3_version_02_final_feb2009.pdf

\section{NORMAN Newsletters:}

http://www.norman-network.net/index_php.php?module= public/others/newsletter

NORMAN recommendations for research topics under FP7 (Research Agenda):

http://www.norman-network.net/public_docs/workshop/ norman_network_reccomendations_topics_fp7cooperationprogr sept08.pdf

NORMAN Joint Programme of Activities for 2009:

http:/www.norman-network.net/index_php.php?module= public/about_us/programme_2009\&menu2=public/about_us/ about_us

\section{The Founding Members of the new NORMAN permanent network:}

- $\quad$ INERIS - Institut National de l'Environnement Industriel et des Risques, Parc Alata, BP 2, 60500 Verneuil-enHalatte, France

- BRGM - Bureau de Recherches Géologiques et Minières, 39-43 Quai André Citroën, Tour Mirabeau, 75739, Paris, France

- WRI/EI - Consortium of Water Research Institute and Environmental Institute, s.r.o., Nabr. Arm. Gen. L. Svobodu 5, 81249 Bratislava, Slovakia

- UBA - Umweltbundesamt - Federal Environment Agency, Wörlitzer Platz 1, 06844 Dessau, Germany

- IAREN - Instituto da Água da Região Norte - Water Institute of the Northern Region - Non profit association, Rua Dr. Eduardo Torres, 229 - 4450-516, Matosinhos, Portugal

- IVL - Svenska Miljoinstitutet AB Box 21060 - Swedish Environmental Research Institute Ltd, S-100 31 Stockholm, Sweden

- BfG - Bundesanstalt für Gewässerkunde - Federal Institute of Hydrology, Am Mainzer Tor 1, 56068 Koblenz, Germany

- Alterra b.v., Droevendaalsesteeg 3a, 6708 PB, Wageningen, The Netherlands 


\section{If you wish to join the network:}

If you wish to join the NORMAN network in 2009 you will find further information on the NORMAN website (http://www.norman-network.net 》 About NORMAN 》 Membership). Your organisation will have to fill in and sign the Declaration of Membership available on the NORMAN website.

\section{You can also contact:}

\section{Valeria DULIO}

Executive Secretary of the NORMAN network INERIS

Rue Jacques Taffanel - Parc Technologique ALATA 60550 VERNEUIL EN HALATTE (France)

E-mail address: valeria.dulio $<$ at $>$ ineris.fr 